\title{
Determinants of consumption-day amounts applicable for the estimation of usual dietary intake with a short 24-h food list
}

\author{
Johanna Freese ${ }^{1} *$, Mihaela Pricop-Jeckstadt ${ }^{2}$, Thorsten Heuer ${ }^{3}$, Matthias Clemens ${ }^{4}$, Heiner Boeing ${ }^{4}$, \\ Sven Knüppel ${ }^{4}$ and Ute Nöthlings ${ }^{1}$ \\ ${ }^{1}$ Department of Nutrition and Food Sciences, Nutritional Epidemiology, University of Bonn, Endenicher Allee 11-13, 53115 Bonn, Germany \\ ${ }^{2}$ Institute for Medical Informatics and Biometry, TU-Dresden, Fetscherstr. 74, 01307 Dresden, Germany \\ ${ }^{3}$ Department of Nutritional Behaviour, Max Rubner-Institut, Federal Research Institute of Nutrition and Food, Haid-und-Neu-Str. 9, 76131 \\ Karlsrube, Germany \\ ${ }^{4}$ Department of Epidemiology, German Institute of Human Nutrition Potsdam-Rebbruecke, Arthur-Scheunert-Allee 114-116, 14558 Nuthetal, \\ Germany
}

(Received 8 May 2016 - Accepted 29 June 2016)

Journal of Nutritional Science (2016), vol. 5, e35, page 1 of 6

doi:10.1017/jns.2016.26

Abstract

Next to the information on frequency of food consumption, information on consumption-day amounts is important to estimate usual dietary intake in epidemiological studies. Our objective was to identify determinants of consumption-day amounts to derive person-specific standard consumption-day amounts applicable for the estimation of usual dietary intake using separate sources to assesss information on consumption probability and amount consumed. 24-h Dietary recall data from the German National Nutrition Survey II ( $n=8522$; aged 20-80 years) conducted between 2005 and 2007 were analysed for determinants of consumption-day amounts of thirty-eight food and beverage groups using LASSO variable selection for linear mixed-effects models. Determinants included sex, age, BMI, smoking status, years of education, household net income, living status and employment status. Most often, sex, age and smoking status were selected as predictors for consumption-day amounts across thirty-eight food groups. In contrast, living with a partner, employment status and household net income were less frequently chosen. Overall, different determinants were of relevance for different food groups. The number of selected determinants ranged from eight for coffee and juice to zero for cabbage, tea, root vegetables, leafy vegetables, fruit vegetables, legumes, offal, vegetable oils, and other fats. For the estimation of usual dietary intake in a combined approach with a 24-h food list, person-specific standard consumption-day amounts could be used. Sex, age and smoking status were shown to be the most relevant predictors in our analysis. Their impact on the estimation of usual dietary intake needs to be evaluated in future studies.

Key words: Dietary assessment: Nutritional epidemiology: Large-scale settings: Usual dietary intake: Statistical modelling

It has been suggested that approaches of combining instruments, e.g. repeated 24-h dietary recall (24HDR) with a FFQ, may provide high-quality dietary information, especially for the assessment of foods that are not consumed every day ${ }^{(1-5)}$. These methods presume that the usual dietary intake of a subject equals the consumption probability of a food on a given day multiplied by the average amount of intake of that food on a typical consumption day. In theory, the information on consumption probability and consumption-day amount could be derived from different instruments. It has been previously noted that most of the variation in food consumption is explained by frequency of intake ${ }^{(6,7)}$. We therefore recently proposed the application of a short $24-\mathrm{h}$ food list for the estimation of consumption probability, which only enquires

Abbreviations: 24HDR, 24-h dietary recall; NVS II, German National Nutrition Survey II.

* Corresponding author: Dr J. Freese, fax +49 228 7360492, email j.freese@uni-bonn.de

(C) The Author(s) 2016. This is an Open Access article, distributed under the terms of the Creative Commons Attribution licence (http://creativecommons.org/licenses/by/4.0/), which permits unrestricted re-use, distribution, and reproduction in any medium, provided the original work is properly cited. 
about whether or not a food was consumed on the previous day ${ }^{(8)}$. Individual information on amounts consumed is replaced by standard consumption-day amounts. The 24-h food list is intended to be used in a combined approach with an FFQ to estimate usual dietary intake. This approach is currently implemented in a large German cohort study, the German National Cohort ${ }^{(9,10)}$, and reflects an effort to reduce demands on time in dietary assessment in large-scale settings.

Information on standard consumption-day amounts of foods may be derived from different sources: representative national dietary survey data or detailed dietary assessments on a subgroup of the population under study are two examples. Furthermore, standard consumption-day amounts can either be assigned identically for all study participants, or specifically stratified for subgroups of the study population such as men and women ${ }^{(7)}$, or estimated by using appropriate statistical models ${ }^{(1,3)}$.

Thus far, there has been some research on factors influencing both the amount of foods consumed and frequency of consumption. It has been shown that amounts consumed differed by sex, age or $\mathrm{BMI}^{(7,11)}$. According to previous research in surveys, sociodemographic factors such as education ${ }^{(12)}$, income $^{(13)}$, family status ${ }^{(14)}$, socio-economic status ${ }^{(15)}$ and smoking status ${ }^{(16,17)}$ were associated with food and beverage consumption. However, these studies looked at the factors separately, so that it remains unclear whether or not the factors have a joint impact on the individual consumption-day amounts. Moreover, different factors may be of relevance for amounts of different groups of foods and beverages.

Implementing person-specific standard consumption-day amounts, also differently across food groups, may lead to more precise estimates of individual usual dietary product intake. Therefore, the aim of the present study was to identify determinants explaining variation in consumption-day amounts across different food groups using national dietary survey data.

\section{Subjects and methods}

\section{Survey methodologies and study population}

The German National Nutrition Survey II (NVS II) was carried out from November 2005 to January 2007 in a representative sample of German-speaking residents ${ }^{(18)}$. Amongst others, dietary intake in the NVS II was assessed on two nonconsecutive days using EPIC-Soft (renamed GloboDiet in 2014), a well-established computerised 24HDR, conducted by trained interviewers over the telephone ${ }^{(19,20)}$. The two 24HDR were randomly sampled and approximately proportionally distributed over weekdays and weekends (75 and 25 $\%$, respectively) ${ }^{(20)}$. The interviews were open-ended and included probing questions and integrated quality checks. In detail, participants were asked to recall the foods and drinks they had consumed the previous day. A quick list was used to report all foods and beverages consumed. This was followed by a detailed enquiry on food preparation, portion size, brand names or additions ${ }^{(19,21)}$. Portion size was assessed using household measures, standard units and a picture booklet ${ }^{(20)}$. In the end, additional data checks were conducted by the research team to identify and correct for data input errors (e.g. for large and small quantities, extremes in the calculated energy and macronutrient intake).

In total, 12502 participants of the NVS II aged 20-80 years completed two EPIC-Soft 24HDR. For the present study, NVS II participants were excluded if they were breastfeeding or pregnant women, or if they had a particular diet such as a slimming diet or a diet related to health conditions $(n=$ 2672). It was assumed that those study participants did not consume typical amounts of foods and beverages. In addition, NVS II participants with missing values on socio-economic factors and smoking status were excluded $(n=1308)$. This resulted in an analytical study population of 8522 participants.

Demographic, socio-economic and lifestyle variables were assessed in a computer-assisted personal interview ${ }^{(18)}$. Years of education were determined according to the International Standard Classification of Education $1997^{(22)}$. Anthropometric measures were assessed in three different ways: (1) measures of weight and height following a standardised protocol ${ }^{(23)} \quad(n=5809)$; (2) self-reported weight and height $(n=2694)$; and (3) for participants with missing information on weight and height, the BMI was calculated based on sex- and age-specific mean values for BMI from NVS II participants with information on measured or self-reported weight and height $(n=19)$.

\section{Classification of food groups}

Foods were grouped according to a newly developed tool, the short 24 -h food list ${ }^{(8)}$. Food and drink items were categorised into thirty-eight groups of food and beverages. The food groups and the general food items within each group are listed in Supplementary Table S1. For each food group, the consumption-day amount, defined as the amount consumed in $g$ per $\mathrm{d}$, was calculated.

\section{Statistical analysis}

Descriptive statistics of the study population are presented as percentages for categorical variables and as mean and standard deviation for continuous variables.

To check for multicollinearity between determinants, the variance inflation factor was calculated. The $\varphi$ coefficient was determined to measure the association between predictors for consumption-day amounts. The analyses were performed using the statistical software package SAS (version 9.4, 2008; SAS Institute Inc.).

The consumption-day amount $(\mathrm{g} / \mathrm{d})$ was treated as the dependent variable. Sex, age (years), BMI $\left(\mathrm{kg} / \mathrm{m}^{2}\right)$, smoking status (current; former; never), years of education (9-10; 12-13; 14-16; 17-18 years), living together with a partner (yes; no), household net income $(<1500 € ; 1500 €$ to $<3000 € ; \geq 3000$ $€)$ and employment status (yes; no) were investigated as determinants.

To determine the most relevant predictors of consumptionday amounts, the LASSO, as a popular shrinkage and variable 
selection method for linear mixed-effects models, was used (see Supplementary Methods for detailed information on the statistics). The dependent variable was Box-Cox transformed to obtain normally distributed residuals ${ }^{(24)}$. Further statistical analysis was conducted using the package lmmlasso in $\mathrm{R}$ (version 3.1.1). To pick the most suitable LASSO model, the Bayesian information criterion was used. The Bayesian information criterion is advocated in the original article proposing the LASSO for linear mixed-effects models based on the authors' empirical experience ${ }^{(25)}$.

\section{Results}

The analytical sample comprised 3989 men (47\%) and 4533 women $(53 \%)$ (Table 1). Overall, the mean age of the study population was 48 years and the mean BMI was $26 \cdot 0 \mathrm{~kg} / \mathrm{m}^{2}$.

The results of the LASSO variable selection explaining the consumption-day amounts across the thirty-eight food and beverage groups, using the Bayesian information criterion as the selection criterion, are shown in Tables 2 and 3. Overall, sex was selected as the predictor most often $(n=26)$ followed by age $(n=21)$ and smoking status $(n=18)$ (Table 2$)$. In contrast, employment status, living with a partner and household net income were chosen less frequently. Years of education and BMI were selected for the models of thirteen and twelve food groups, respectively. With respect to single food groups, all eight determinants were of relevance for the consumptionday amount of coffee and juice (Table 3). In contrast, no predictor was selected for the models of the food groups cabbage, legumes, offal, tea, fruit vegetables, leafy vegetables, root

Table 1. Characteristics of participants of the German National Nutrition Survey II $(n=8522)$

(Percentages, mean values and standard deviations)

\begin{tabular}{|c|c|c|c|}
\hline & \multicolumn{3}{|c|}{ Age group (years) } \\
\hline & $20-34$ & $35-64$ & $65-80$ \\
\hline$n$ & 1526 & 5603 & 1393 \\
\hline Female (\%) & 54.9 & 53.6 & 49.6 \\
\hline \multicolumn{4}{|l|}{ Age (years) } \\
\hline Mean & $27 \cdot 6$ & 48.0 & $70 \cdot 0$ \\
\hline SD & 4.4 & $8 \cdot 3$ & 4.2 \\
\hline \multicolumn{4}{|l|}{ BMI $\left(\mathrm{kg} / \mathrm{m}^{2}\right)$} \\
\hline Mean & $24 \cdot 2$ & $26 \cdot 1$ & $27 \cdot 3$ \\
\hline SD & 4.5 & 4.4 & $4 \cdot 1$ \\
\hline \multicolumn{4}{|l|}{ Smoking status (\%) } \\
\hline Never & $52 \cdot 7$ & $45 \cdot 1$ & 61.4 \\
\hline Former & 11.9 & 25.5 & 28.7 \\
\hline Current & 35.5 & 29.3 & 9.9 \\
\hline \multicolumn{4}{|l|}{ Years of education (\%)* } \\
\hline $9-10$ years & 5.9 & 4.8 & $17 \cdot 1$ \\
\hline $12-13$ years & 53.5 & $50 \cdot 4$ & 48.0 \\
\hline $14-16$ years & $22 \cdot 2$ & $21 \cdot 0$ & $16 \cdot 4$ \\
\hline $17-18$ years & $18 \cdot 4$ & 23.8 & $18 \cdot 5$ \\
\hline \multicolumn{4}{|l|}{ Household net income (\%) } \\
\hline$<1500 €$ & 30.4 & $17 \cdot 3$ & $32 \cdot 0$ \\
\hline 1500 to $<3000 €$ & 47.9 & 49.4 & 52.9 \\
\hline$\geq 3000 €$ & 21.7 & 33.4 & $15 \cdot 1$ \\
\hline Living together with a partner (\%) & $57 \cdot 0$ & 82.9 & 76.9 \\
\hline Employed (\%) & 78.0 & 76.9 & 5.9 \\
\hline
\end{tabular}

* According to the International Standard Classification of Education $1997^{(22)}$.
Table 2. Relevance of determinants for consumption-day amounts across thirty-eight food groups using LASSO variable selection*

\begin{tabular}{lc}
\hline Determinant & Food groups with positive selection $(n)$ \\
\hline Sex & 26 \\
Age & 21 \\
Smoking status & 18 \\
Years of education & 14 \\
BMl & 12 \\
Employment & 10 \\
Living with a partner & 9 \\
Household net income & 8
\end{tabular}

* Selection criterion: Bayesian information criterion.

vegetables, vegetable oils and other fats. For cake, potatoes and poultry, sex was the only determinant selected, whereas for the food group other vegetables, solely age was chosen.

Both the variance inflation factor and the $\varphi$ coefficient indicated a correlation only of the determinants years of education and household net income in the models (variance inflation factor $>2 ; r \varphi=0.37$ ) (data not shown).

\section{Discussion}

The findings of the present study indicate that all demographic and socio-economic factors investigated were relevant for the consumption-day amount of specific food groups. However, differences in importance across food and beverage groups were observed. Sex was shown to be the most relevant predictor followed by age and smoking status. In contrast, household net income was less important. Interestingly, BMI was overall less relevant for consumption-day amount of food groups than expected.

The estimation of usual dietary intake in large-scale prospective studies is a current topic of interest. It has been suggested that an approach of combining instruments such as repeated 24HDR and FFQ may provide high-quality dietary information, especially for the assessment of foods that are not consumed every day ${ }^{(1-5)}$. These methods presume that the usual dietary intake of a subject equals the consumption probability of a food on a given day multiplied by the average amount of intake of that food on a typical consumption day. Although multiple administrations of detailed 24HDR would be optimal, this is impracticable in large-scale cohort studies due to the associated high costs and time expenditure ${ }^{(26)}$. Detailed web-based 24HDR developed for self-administered use are likely to be more cost-effective with respect to administration ${ }^{(27)}$, but might still be time-consuming for the study participant, and are only available in the $\mathrm{UK}^{(28)}$ and the $\mathrm{USA}^{(29)}$ so far. For Germany, we recently proposed a short 24-h food list, which only enquires about whether or not a food was consumed on the previous day ${ }^{(8)}$. Instead of individual amounts consumed, standard consumption-day amounts can be applied for the estimation of usual dietary intake.

Our study indicated that different determinants were of importance for different food groups. For some food groups, six to eight predictors were important whereas for other groups, none was chosen. Overall, sex, age and smoking status were 
Table 3. Selected determinants for consumption-day amounts across thirty-eight food and beverage groups*

\begin{tabular}{|c|c|c|c|c|c|c|c|c|}
\hline Food group $†$ & Sex & Age & Smoking status & Years of education & BMI & Employment & Living with a partner & Household net income \\
\hline Coffee & $x$ & $x$ & $x$ & $x$ & $x$ & $x$ & $x$ & $x$ \\
\hline Juice & $x$ & $x$ & $x$ & $x$ & $x$ & $x$ & $x$ & $x$ \\
\hline Processed meat & $\mathrm{x}$ & $\mathrm{x}$ & $\mathrm{x}$ & $\mathrm{x}$ & $\mathrm{x}$ & $\mathrm{x}$ & & $\mathrm{x}$ \\
\hline Other non-alcoholic drinks & $\mathrm{x}$ & $\mathrm{x}$ & $\mathrm{x}$ & $\mathrm{x}$ & $\mathrm{x}$ & $\mathrm{x}$ & $\mathrm{x}$ & \\
\hline Bread & $\mathrm{x}$ & & $\mathrm{x}$ & & $\mathrm{x}$ & $\mathrm{x}$ & $x$ & $x$ \\
\hline Milk and dairy products & $x$ & $x$ & $x$ & $x$ & & $x$ & $x$ & \\
\hline Wine & $x$ & $x$ & $x$ & & $x$ & $x$ & & $x$ \\
\hline Beer & $x$ & $x$ & $x$ & & $x$ & & $x$ & $x$ \\
\hline Cheese & $x$ & $x$ & & $x$ & & $x$ & & $x$ \\
\hline Butter & $x$ & $x$ & $x$ & $x$ & $x$ & & & $x$ \\
\hline Other alcoholic drinks & $x$ & $x$ & $x$ & $x$ & $x$ & & & \\
\hline Nuts & $x$ & $x$ & $x$ & $x$ & & $x$ & & \\
\hline Eggs & $x$ & $x$ & $x$ & & & & $x$ & \\
\hline Meat & $x$ & $x$ & $x$ & & $x$ & & & \\
\hline Cereals & $x$ & $x$ & $x$ & & & & $x$ & \\
\hline Soft drinks & $x$ & $x$ & $x$ & $x$ & & & & \\
\hline Sugar & $x$ & $x$ & & & $x$ & & $x$ & \\
\hline Fresh fruits & & $x$ & $x$ & $x$ & & & & \\
\hline Sauces & $x$ & $x$ & $x$ & & & & & \\
\hline Pasta/rice & $x$ & $x$ & & & $x$ & & & \\
\hline Soup & $x$ & & & $x$ & & & & \\
\hline Other fruits & $x$ & & & $x$ & & & & \\
\hline Fish & $x$ & & & $x$ & & & & \\
\hline Spirits & & $\mathrm{x}$ & $\mathrm{x}$ & & & & & \\
\hline Margarine & $x$ & & & & & $x$ & & \\
\hline Cake & $x$ & & & & & & & \\
\hline Potatoes & $x$ & & & & & & & \\
\hline Other vegetables & & $x$ & & & & & & \\
\hline Poultry & $x$ & & & & & & & \\
\hline
\end{tabular}

* LASSO variable selection for linear-effect models was used; selection criterion: Bayesian information criterion.

†Food groups cabbage, tea, root vegetables, leafy vegetables, fruit vegetables, legumes, offal, vegetable oils and other fats are not shown because no determinant was selected for those food groups.

shown to be mostly relevant, but for some food groups further determinants carried information. Thus, if available, personspecific consumption-day amounts could be predicted differently across foods. However, the gain in information for the estimation of usual dietary intake might have to be evaluated in future research.

Information on standard consumption-day amounts may be derived from different sources of data. First, national dietary survey data such as the NVS II in Germany can be used ${ }^{(18)}$. Second, the application of $24 \mathrm{HDR}$ on a subgroup of the population under study can be conducted. National survey data might provide representative data of the population of a country. Moreover, survey sample sizes are typically large and, thus, the variety in the pictured diet might be high. This may lead to more reliable data for the computation of standard consumption-day amounts. In contrast, the application of $24 \mathrm{HDR}$ in a subgroup of the population under study might be preferable for specific ethnic populations.

To take into account covariates predicting consumption-day amounts, two general strategies are possible. First, standard consumption-day amounts could be derived using stratified mean or median intakes of the respective food items as it has been done previously ${ }^{(7,30)}$; and second, amounts could be estimated by using appropriate statistical models ${ }^{(1,3,31)}$. Tooze et al. ${ }^{(1)}$ stated that using statistical models may result in a more efficient estimation than does stratification. Especially when applying a number of person-specific factors, as is suggested by the present findings, stratification may lead to very small samples for specific strata combinations. Therefore, the application of prediction models seems to be advantageous for the proposed approach.

Of note, person-specific standard consumption-day amounts can only be used for determinants which actually have been measured in the respective study. All of the proposed determinants are nowadays typically assessed in nutritional epidemiological studies meaning that no additional assessment effort would be necessary ${ }^{(32,33)}$. However, for household net income, which was one of the factors proposed to be important for consumption-day amounts, no general standards are available for the generation of categories. Even if prediction models are applied instead of stratification, this variable needs to be categorised for analysis. Thus, future research should evaluate the application of different strata according to the estimation of usual dietary intake. A correlation between the variables household net income and years of education was observed. Thus, the use of one of the variables would be sufficient for the application of person-specific standard consumption-day amounts.

Our study has some limitations. First, to identify determinants that explain variation in consumption-day amounts of foods and beverages, food items of different serving size were combined into commonly used food groups, reducing some of the variation in the data. Second, although a broad range of possibly informative socio-economic and 
anthropometric factors was considered, there may be other important determinants such as physical activity that additionally influence the amount consumed. It was, however, not possible to include this variable in our analysis since information on physical activity in the NVS II was assessed for a subgroup of participants only. The remaining study population would have weakened the analysis. Third, the application of personspecific standard consumption-day amounts is limited by sufficient variation of determinants in a study population.

The fact that representative contemporary German dietary survey data were used to analyse determinants of consumption-day amounts can be considered a strength. Thus, the results are suitable for use all over Germany. State-of-the-art variable selection procedures were applied to analyse the relevance of consumptionday amount predictors. The application of person-specific standard consumption-day amounts may lead to more precise estimates of usual dietary intake in large-scale settings that are limited by the costs and logistics of data collection.

\section{Conclusion}

For the estimation of usual dietary intake in combined approaches, person-specific standard consumption-day amounts could be used. Sex, age and smoking status were shown to be the most relevant determinants in our analysis. However, for some food groups further determinants were explanatory, suggesting, if possible, to predict consumption-day amounts based on the whole set of relevant variables. The impact of person-specific standard consumption-day amounts for the estimation of intake of single food items might need to be evaluated in future research.

\section{Supplementary material}

The supplementary material for this article can be found at http://dx.doi.org/10.1017/jns.2016.26

\section{Acknowledgements}

The original survey (NVS II) was funded by the German Federal Ministry of Food, Agriculture and Consumer Protection.

The authors' contributions are as follows: U. N., J. F., H. B. and S. K. designed the research; J. F. was responsible for manuscript preparation; J. F., M. P.-J. and S. K. were responsible for data handling, statistical analyses and data interpretation; M. P.-J. was involved in manuscript preparation; U. N., H. B., M. C. and T. H. contributed to data interpretation. All authors critically reviewed the manuscript. All authors read and approved the final version of the manuscript.

The authors declare that they have no conflicts of interest.

\section{References}

1. Tooze JA, Midthune D, Dodd KW, et al. (2006) A new statistical method for estimating the usual intake of episodically consumed foods with application to their distribution. J Am Diet Assoc 106, 1575-1587.
2. Kipnis V, Midthune D, Buckman DW, et al. (2009) Modeling data with excess zeros and measurement error: application to evaluating relationships between episodically consumed foods and health outcomes. Biometrics 65, 1003-1010.

3. Haubrock J, Nothlings U, Volatier JL, et al. (2011) Estimating usual food intake distributions by using the multiple source method in the EPIC-Potsdam Calibration Study. J Nutr 141, 914-920.

4. Carroll RJ, Midthune D, Subar AF, et al. (2012) Taking advantage of the strengths of 2 different dietary assessment instruments to improve intake estimates for nutritional epidemiology. Am J Epidemiol $175,340-347$.

5. Subar AF, Dodd KW, Guenther PM, et al. (2006) The Food Propensity Questionnaire: concept, development, and validation for use as a covariate in a model to estimate usual food intake. J Am Diet Assoc 106, 1556-1563.

6. Heady JA (1961) Diets of bank clerks. Development of a method of classifying the diets of individuals for use in epidemiological studies. J R Stat Soc Ser A (Gen) 124, 336-361.

7. Noethlings U, Hoffmann K, Bergmann MM, et al. (2003) Portion size adds limited information on variance in food intake of participants in the EPIC-Potsdam study. J Nutr 133, 510-515.

8. Freese J, Feller S, Harttig U, et al. (2014) Development and evaluation of a short 24-h food list as part of a blended dietary assessment strategy in large-scale cohort studies. Eur J Clin Nutr 68, 324-329.

9. Ahrens W, Greiser H, Linseisen J, et al. (2014) [The design of a nationwide cohort study in Germany: the pretest studies of the German National Cohort (GNC)]. Bundesgesundhbl Gesundheitsforsch Gesundheitsschutz 57, 1246-1254.

10. German National Cohort C (2014) The German National Cohort: aims, study design and organization. Eur J Epidemiol 29, 371-382.

11. Clapp JA, McPherson RS, Reed DB, et al. (1991) Comparison of a food frequency questionnaire using reported vs standard portion sizes for classifying individuals according to nutrient intake. $J \mathrm{Am}$ Diet Assoc 91, 316-320.

12. Worsley A, Blasche R, Ball K, et al. (2004) The relationship between education and food consumption in the 1995 Australian National Nutrition Survey. Public Health Nutr 7, 649-663.

13. Worsley A, Blasche R, Ball K, et al. (2003) Income differences in food consumption in the 1995 Australian National Nutrition Survey. Eur J Clin Nutr 57, 1198-1211.

14. Billson H, Pryer JA \& Nichols R (1999) Variation in fruit and vegetable consumption among adults in Britain. An analysis from the Dietary and Nutritional Survey of British adults. Eur J Clin Nutr 53, 946-952.

15. Hulshof KF, Brussaard JH, Kruizinga AG, et al. (2003) Socio-economic status, dietary intake and $10 \mathrm{y}$ trends: the Dutch National Food Consumption Survey. Eur J Clin Nutr 57, 128-137.

16. Margetts BM \& Jackson AA (1993) Interactions between people's diet and their smoking habits: the Dietary and Nutritional Survey of British adults. BMJ 307, 1381-1384.

17. Padrao P, Lunet N, Santos AC, et al. (2007) Smoking, alcohol, and dietary choices: evidence from the Portuguese National Health Survey. BMC Public Health 7, 138.

18. Heuer T, Krems C, Moon K, et al. (2015) Food consumption of adults in Germany: results of the German National Nutrition Survey II based on diet history interviews. Br J Nutr 113, 16031614.

19. Slimani N, Deharveng G, Charrondiere RU, et al. (1999) Structure of the standardized computerized 24-h diet recall interview used as reference method in the 22 centers participating in the EPIC project. European Prospective Investigation into Cancer and Nutrition. Comput Methods Programs Biomed 58, 251-266.

20. Eisinger-Watzl M, Strassburg A, Ramunke J, et al. (2015) Comparison of two dietary assessment methods by food consumption: results of the German National Nutrition Survey II. Eur J Nutr 54, 343-354.

21. Slimani N, Ferrari P, Ocke M, et al. (2000) Standardization of the 24-h diet recall calibration method used in the European 
Prospective Investigation into Cancer and Nutrition (EPIC): general concepts and preliminary results. Eur J Clin Nutr 54, 900-917.

22. United Nations Educational, Scientific and Cultural Organization (UNESCO) (1997) International Standard Classification of Education. Geneva, Switzerland: UNESCO.

23. Lohmann TG, Roche AF \& Martorell R (1988) Anthropometric Standardization Reference Manual. Champaign, IL: Human Kinetics Books.

24. Box GEP \& Cox DR (1964) An analysis of transformations. J R Stat Soc B 26, 211-252.

25. Schelldorfer J, Buhlmann P \& Van De Geer S (2011) Estimation for high-dimensional linear mixed-effects models using 1 (1)-penalization. Scand J Stat 38, 197-214.

26. Schatzkin A, Subar AF, Moore S, et al. (2009) Observational epidemiologic studies of nutrition and cancer: the next generation (with better observation). Cancer Epidemiol Biomarkers Prev 18, 1026-1032.

27. Illner AK, Freisling H, Boeing H, et al. (2012) Review and evaluation of innovative technologies for measuring diet in nutritional epidemiology. Int J Epidemiol 41, 1187-1203.
28. Carter MC, Albar SA, Morris MA, et al. (2015) Development of a UK online 24-h dietary assessment tool: myfood24. Nutrients 7 , 4016-4032.

29. Subar AF, Kirkpatrick SI, Mittl B, et al. (2012) The automated selfadministered 24-h dietary recall (ASA24): a resource for researchers, clinicians, and educators from the National Cancer Institute. J Acad Nutr Diet 112, 1134-1137.

30. Lyons J, Walton J \& Flynn A (2013) Development of an online database of typical food portion sizes in Irish population groups. J Nutr Sci 2, e25.

31. Harttig U, Haubrock J, Knuppel S, et al. (2011) The MSM program: web-based statistics package for estimating usual dietary intake using the multiple source method. Eur J Clin Nutr 65, Suppl. 1, S87-S91.

32. Wichmann HE, Kaaks R, Hoffmann W, et al. (2012) [The German National Cohort]. Bundesgesundhbl Gesundheitsforsch Gesundheitsschutz 55, 781-787.

33. Riboli E, Hunt KJ, Slimani N, et al. (2002) European Prospective Investigation into Cancer and Nutrition (EPIC): study populations and data collection. Public Health Nutr 5, 1113-1124. 